\title{
Study on the Rate Performance of $\mathrm{LiCo}_{1 / 3} \mathrm{Ni}_{1 / 3} \mathrm{Mn}_{1 / 3} \mathrm{O}_{2}$
}

\author{
Dongyun ZHANG ${ }^{1}$, Juan $\mathrm{YI}^{2}$, Qun WEI ${ }^{3}$, Kun LIU ${ }^{1}$, Zhenzhen FAN ${ }^{2}$ \\ and Peixin $\mathrm{ZHANG}^{2^{*}}$ \\ ${ }^{1}$ School of Chemistry and Chemical Engineering, Guangxi University, Nanning 530004, China \\ ${ }^{2}$ School of Chemistry and Chemical Engineering, Shenzhen University, Shenzhen 518060, China \\ ${ }^{3}$ School of Science, Xidian University, Xi'an 710071, China
}

*Corresponding author Email: pxzhang2000@163.com

Keywords: $\mathrm{LiCo}_{1 / 3} \mathrm{Mn}_{1 / 3} \mathrm{Ni}_{1 / 3} \mathrm{O}_{2}$; electrochemical performance; AC impedance

\begin{abstract}
Ternary lithium-ion battery is currently one of the hot cathode materials. In this paper, with acetate of nickel, manganese and cobalt as raw materials and lithium hydroxide as precipitation agent, $\mathrm{LiCo}_{1 / 3} \mathrm{Mn}_{1 / 3} \mathrm{Ni}_{1 / 3} \mathrm{O}_{2}$ was prepared by chemical coprecipitation method. LAND charge-discharge testing was used to study the electrochemical performance of materials at different rates $(0.5 \mathrm{C}, 1 \mathrm{C}, 2 \mathrm{C})$, and $\mathrm{AC}$ impedance spectroscopy was employed to study the rate performance and reasons of cyclical stability. The results showed that the stable SEM film formed under high rate was the main reason for the increased rate.
\end{abstract}

\section{Introduction}

Cathode material is one of the key technologies constraining the development of high-performance lithium-ion batteries. Currently hot cathode materials are mainly olivine-type $\mathrm{LiFePO}_{4}, \mathrm{LiCoO}_{2}$ and $\mathrm{LiNiO}_{2}$ with layered structure, and $\mathrm{LiMn}_{2} \mathrm{O}_{4}$ with spinal structure. $\mathrm{LiFePO}_{4}$ is low-cost, rich in raw materials, non-toxic and environment-friendly. However, its electronic and ionic conductivity is low and tap density is relatively low[1]. $\mathrm{LiCoO}_{2}$, on the other hand, has excellent electrochemical cycling performance and is the earliest lithium-ion battery cathode material achieving commercialization. But its resource is limited and it has greater toxicity[2]. $\mathrm{LiNiO}_{2}$ has a higher discharge capacity, but its structural stability is poor, and the preparation conditions are harsh, which limits its commercial applications [3]. $\mathrm{LiMn}_{2} \mathrm{O}_{4}$ is rich in raw materials, but its structure is unstable and prone to Jahn-Teller effect, which leads to poor cycling performance $[4,5]$.

In 2003, Naoaki[6] first synthesized $\mathrm{LiCo}_{1 / 3} \mathrm{Mn}_{1 / 3} \mathrm{Ni}_{1 / 3} \mathrm{O}_{2}$, and its excellent performance has attracted great interest[7], including structure studies[8, 9] and charge-discharge mechanism studies[10, 11]. $\mathrm{LiCo}_{1 / 3} \mathrm{Mn}_{1 / 3} \mathrm{Ni}_{1 / 3} \mathrm{O}_{2}$, as a kind of layered lithium-intercalation compound in which cobalt, nickel and manganese are collaborative, has comprehensive advantages of lithium cobalt oxide, lithium nickel oxide and lithium manganese oxide. It not only has the advantage of high capacity by layered structure, but also can maintain the stability of layered structure and has excellent cycling performance, which makes it a potential lithium-ion battery cathode material. 
However, its internal structure and the reaction mechanism of three transition metals cobalt, nickel and manganese during charge and discharge process of the material have been plaguing all researchers.

There are many ways to synthesis $\mathrm{LiCo}_{1 / 3} \mathrm{Mn}_{1 / 3} \mathrm{Ni}_{1 / 3} \mathrm{O}_{2}$, of which chemical precipitation method can get products with excellent performances $[9,12,13]$. In this paper, $\mathrm{LiCo}_{1 / 3} \mathrm{Mn}_{1 / 3} \mathrm{Ni}_{1 / 3} \mathrm{O}_{2}$ was prepared by chemical coprecipitation, and the electrochemical properties under different rates were studied through charge -discharge test, and reasons of rate capability and cycle characteristics were also discussed using AC impedance spectroscopy.

\section{Experimental}

$0.25 \mathrm{M}$ (the sum of cations) aqueous solution was prepared by mixing $\mathrm{Co}(\mathrm{OAC})_{2} \cdot 4 \mathrm{H}_{2} \mathrm{O}$ 、 $\mathrm{Ni}(\mathrm{OAC})_{2} \cdot 4 \mathrm{H}_{2} \mathrm{O}$ and $\mathrm{Mn}(\mathrm{OAC})_{2} \cdot 4 \mathrm{H}_{2} \mathrm{O}$ according to stoichiometric ratio, and then under the conditions of high-speed stirring and $45^{\circ} \mathrm{C}$, this solution and $\mathrm{LiOH} \cdot \mathrm{H}_{2} \mathrm{O}$ were simultaneously added to a reaction solution in a container with the solution's PH maintained between $12 \sim 13$. After the reaction, $\mathrm{LiCo}_{1 / 3} \mathrm{Mn}_{1 / 3} \mathrm{Ni}_{1 / 3} \mathrm{O}_{2}$ coprecipitation precursor was obtained through ultrasonic dispersion for a certain time. The precursor suspension was then filtered, dried, mixed with $\mathrm{LiOH}$. $\mathrm{H}_{2} \mathrm{O}$ (solid), milled, pressed, sintered at $900{ }^{\circ} \mathrm{C}$ for 12 hours to obtain the products.

The prepared sample, acetylene black and binder polyvinylidene fluoride (PVDF) were mixed into uniform powder by the mass ratio of $85: 10: 5$. The mixture then coats on aluminum foil to get lithium-ion battery cathode plate. With metal lithium(99.9\%) as anode, Cellgard $2300 \mathrm{PE} / \mathrm{PP} / \mathrm{PE}$ composite membrane as the seperator, $1 \mathrm{M} \mathrm{LiPF}_{6} / \mathrm{EC}+\mathrm{DMC}$ (volume ratio 1:1) as the electrolyte, button cells were assembled in Ar-filled, dry and anaerobic $\left(\mathrm{H}_{2} \mathrm{O}<0.1 \mathrm{ppm}, \mathrm{O}_{2}<0.1 \mathrm{ppm}\right)$ glove box (UNILab2000, Germany M. Braun Inc.).

Charge-discharge test of assembled batteries was carried out by the Land BS9300 programmed automatic electrochemical tester, the charge-discharge voltage being set at range of $2.7 \sim 4.5 \mathrm{~V}$. AC impedance measurement was done using CHI 660A electrochemical workstation (CH Inc. USA), by setting the scanning frequency range $10 \mathrm{mHz} \sim 100 \mathrm{KHz}$.

\section{Results and discussion}

Study on charge-discharge at different rates. Shown in Figure 1 is the curve of cycle performance at different discharge rates. Sample I was charged and discharged at $0.1 \mathrm{C}$; sample II was first charged and discharged for 100 times at $0.5 \mathrm{C}$, and then 100 times at $1 \mathrm{C}$; sample III was first charged and discharged for 100 times at $2 \mathrm{C}$, and then 100 times at $1 \mathrm{C}$. The figure shows that sample I has the highest discharge capacity $(173.3 \mathrm{mAh} / \mathrm{g})$ while charge and discharge at $0.1 \mathrm{C}$ and decreases to below $145 \mathrm{mAh} / \mathrm{g}$ after 55 cycles. The maximum discharge capacity of sample II reaches to $155 \mathrm{mAh} / \mathrm{g}$ at $0.5 \mathrm{C}$, and it remains $153.3 \mathrm{mAh} / \mathrm{g}$ after 100 cycles. The biggest discharge capacity of sample III is up to $142.8 \mathrm{mAh} / \mathrm{g}$ at $2 \mathrm{C}$ and it remains $141.4 \mathrm{mAh} / \mathrm{g}$ after 100 cycles, which indicates this material has a good cycle performance. The figure also shows the discharge capacity of the sample has increased, but the cycle stability of the sample only improves at discharge rate of $0.5 \mathrm{C}$ and $2 \mathrm{C}$. In general, the discharge capacity and cycle properties of cathode materials will decrease or get worse with the extended times of charge and discharge cycles [6, 12]. However, in this research, discharge capacity of prepared batteries gradually decreases with the extended cycle time, but the samples maintained good cycle performance at $0.5 \mathrm{C}$ and $2 \mathrm{C}$ rates, 
which indicates the prepared $\mathrm{LiCoB}_{1 / 3 \mathrm{~B}} \mathrm{NiB}_{1 / 3 \mathrm{~B}} \mathrm{MnB}_{1 / 3 \mathrm{~B}} \mathrm{OB}_{2 \mathrm{~B}}$ has an excellent high-rate cycling performance.

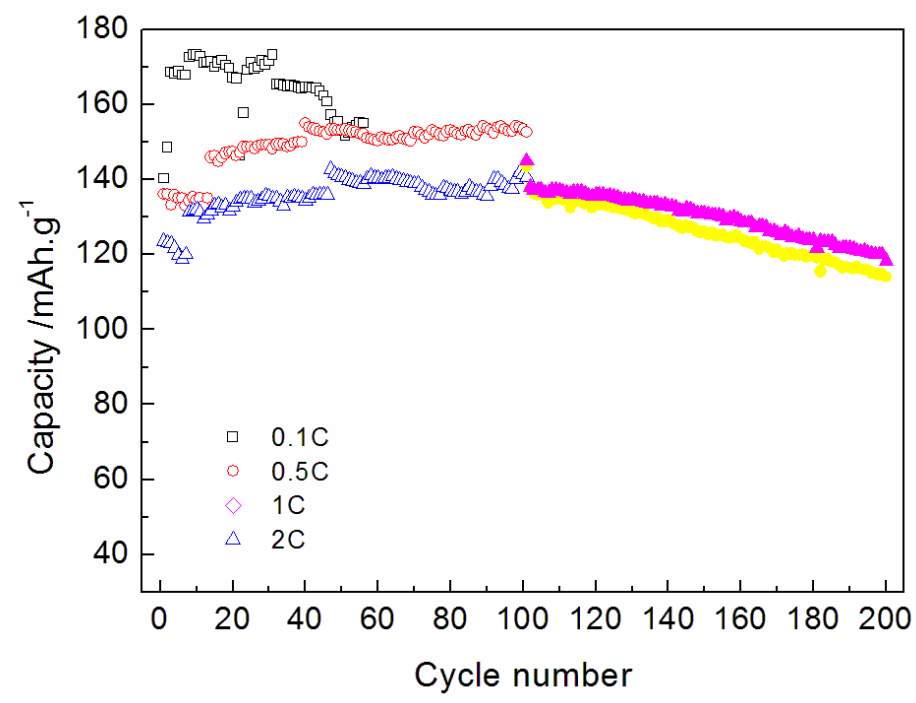

Fig. 1 The cycling performance under different magnification

To further study the cycle performance, a new round of charge and discharge tests of samples II and III at $1 \mathrm{C}$ were carried out after the end of 100 cycles (constant charging voltage is $4.5 \mathrm{~V}$, the same hereinafter) and the test results are shown in Figure 1. As shown in the figure, the two samples both showed good cycle performance after 100 charge-discharge cycles at $1 \mathrm{C}$, and charge-discharge curves almost coincided, and the capacity decrement rates of samples II and III were $18.3 \%$ and $20.5 \%$ respectively after the second 100 cycles. Overall, the cathode material prepared in the experimental conditions in this study showed good cycling performance at high rates as well as high-voltage

AC impedance analysis. AC impedance testing is a very good method for further exploring the reasons for improved cycling performance[14]. In this paper, AC impedance tests of samples III (100 cycles under $2 \mathrm{C}$ ) and sample II (100 cycles under $0.5 \mathrm{C}$, then 100 cycles under $0.2 \mathrm{C}$ ) were carried out respectively and test results are shown in Figure 2. Simulations using the equivalent circuit are shown in Figure 3. Table 1 gives the fitted data of EIS spectra.

It can be seen from Table 1 that the selected equivalent circuit fits the EIS spectra very well, and the fitting error is small. By comparing equivalent circuit parameters of samples $\mathrm{O}, \mathrm{A}, \mathrm{B}$ in table 1 , solution resistance $R_{S}\left(R_{1}\right)$ increases gradually with the increased cycles. The charge transfer resistance $R_{t}\left(R_{2}\right)$ first decreases and then increases, the charge transfer resistance of sample $A$ is the smallest, indicating its largest electronic conductivity. The open circuit voltages of samples $\mathrm{O}, \mathrm{A}$ and $\mathrm{B}$ were $3.659 \mathrm{~V}, 3.7 \mathrm{~V}, 3.642 \mathrm{~V}$ before $\mathrm{AC}$ impedance measurement was carried out. The open circuit voltage of sample $\mathrm{A}$ is the largest, which indicates the amount of its lithium extrusion is relatively large, and the lithium "saturation" phenomenon doesn't happen in the material indicating its electronic conductivity is good. $\mathrm{R}_{3}$ is the resistance of SEI film on the surface of electrode, W-R represents the resistance caused by the mass transfer process during charge-discharge process. It can be seen from Table 1 that the film resistance is rising, while the diffusion impedance first decreases and then increases with the increase of cycles. Therefore, the improvement of material electronic conductivity should be due to the decrease of mass transfer resistance. It can be found that the increasing rate of SEI film significantly gets smaller compared with two increased impedance values, which indicates electrode acts on electrolyte spontaneously to form SEI film. On the other 
hand, this resulting SEI film will inhibit the continued formation[15, 16] in turn. Therefore it is a contradictory process and finding the balance point will be helpful to the improvement in the cycling performance of materials. In addition, CPE2-n and Wn first decreases and then increases with the increased immersion time of electrode in electrolyte, indicating that the SEI film on the electrode surface tends to be uniform and stable with the increased contact time with the electrolyte. However, SEI film will be dissolved and collapse because of too long contact time which causes the increased resistance and decreased uniformity of SEI film. But the three samples are differences in discharge rate except the contact time of electrode and the electrolyte before the AC impedance test.

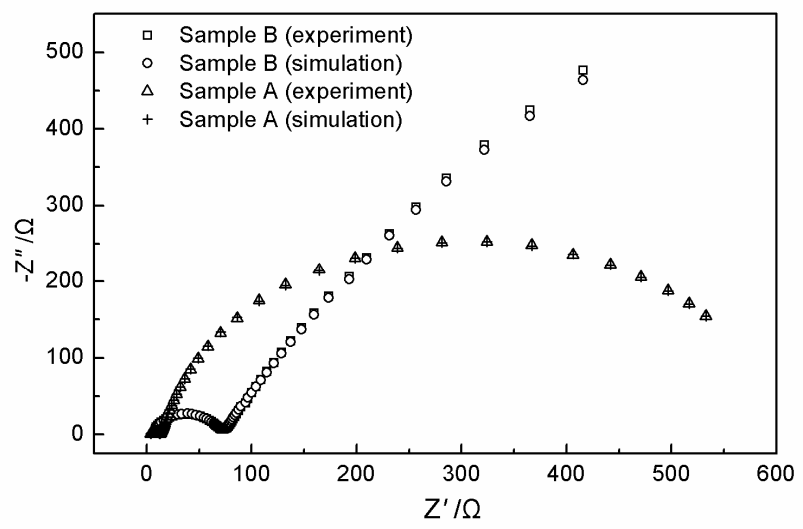

Fig.2 AC impedance spectroscopy of samples

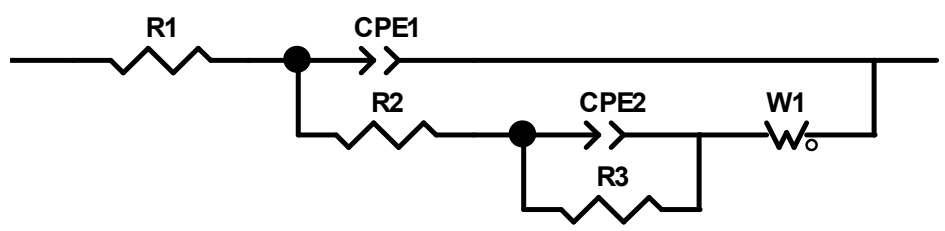

Fig.3 Equivalent circuit employed to fit the experiment AC impedance

Table 1 The time constant and parameters of equivalent circuit obtained for EIS simulation

\begin{tabular}{cccc}
\hline & Sample O & Sample A & Sample B \\
\hline $\mathrm{R}_{1}[\Omega]$ & 2.78 & 3.613 & 6.792 \\
$\mathrm{CPE} 1-\mathrm{Y}_{0}[\mathrm{~F}]$ & $1.0007 \times 10^{-5}$ & $4.1746 \times 10^{-6}$ & $3.9232 \times 10^{-6}$ \\
$\mathrm{CPE} 1-\mathrm{n}$ & 0.8621 & 0.9166 & 0.925 \\
$\mathrm{R}_{2}[\Omega]$ & 12.28 & 7.809 & 58.69 \\
$\mathrm{CPE} 2-\mathrm{Y}_{0}[\mathrm{~F}]$ & 0.016321 & 0.0053457 & 0.011 \\
$\mathrm{CPE} 2-\mathrm{n}$ & 0.89 & 0.92097 & 0.785 \\
$\mathrm{R}_{3}[\Omega]$ & 65.45 & 537.4 & 1025 \\
$\mathrm{~W}-\mathrm{R}[\Omega]$ & 11.18 & 4.219 & 22.47 \\
$\mathrm{~W}-\mathrm{Y}[\mathrm{F}]$ & 0.21389 & 0.09327 & 0.13148 \\
$\mathrm{~W}-\mathrm{n}$ & 0.26889 & 0.23841 & 0.31 \\
$\tau_{0}[\mathrm{~s}]$ & $1.23 \times 10^{-4}$ & $3.26 \times 10^{-5}$ & $2.3 \times 10^{-4}$ \\
$\tau_{1}[\mathrm{~s}]$ & 1.068 & 2.87 & 11.27 \\
\hline & & &
\end{tabular}


According to the fitting data in Table 1, using the time constant formula, it can be obtained how the two state variables-the electrode potential E and the SEI film thickness X change with the length of relaxation process occurring with the disturbances which are caused by the extended contact time of electrode and electrolyte. The time constants $\tau_{0}$ and $\tau_{1}$ in table 1 show that the time constant in impedance spectra of sample A increases, although the rate of increase is not very great, the time constant of sample B increases by almost 4 times, indicating that a relatively stable SEI film formed on the electrode surface during the high rate charge and discharge process. Therefore, the samples are more suitable for high rate discharge, which is consistent with the cycling performance at $0.1 \mathrm{C}$ and $2 \mathrm{C}$ as shown in Figure 1: after 100 cycles at the discharge rate of $2 \mathrm{C}$, the capacity of the sample does not decay, while after 55 cycles at $0.1 \mathrm{C}$, the attenuation capacity is up to $16 \%$.

\section{Conclusions}

The rate performance of cathode material was studied by charge-discharge test and AC impedance spectroscopy. The result shows that the prepared samples are more suitable for high-rate discharge. When charge and discharge test is carried out at the rate of $2 \mathrm{C}$, the material's capacity has no degradation after 100 cycles, and the largest discharge capacity is up to $142.8 \mathrm{mAh} / \mathrm{g}$ and remains up to $141.4 \mathrm{mAh} / \mathrm{g}$ after 100 cycles. The maximum discharge capacity at $0.5 \mathrm{C}$ is $155 \mathrm{mAh} /$ $\mathrm{g}$ and $153.3 \mathrm{mAh} / \mathrm{g}$ after 100 cycles without degradation. The maximum discharge capacity reaches $173.3 \mathrm{mAh} / \mathrm{g}$ at $0.1 \mathrm{C}$, but fades by $16 \%$ after 55 cycles.

AC impedance analysis shows that the sample has a lower charge transfer resistance under high rate $(2 \mathrm{C})$, and the time constant in relaxation process of electrode potential $\mathrm{E}$ is the smallest. Although the resistance of SEI film on the electrode surface increases, it is caused by the long time of immersion in the electrolyte. The impedance time constant of SEI film is large comparatively, but the growth rate is much smaller than the sample after 200 cycles. All these indicate the good cycling performance and high cyclic reversibility of the sample at high rates, which is consistent with the charge-discharge test.

\section{Acknowledgement}

This work was supported by the National Natural Science Foundation of Guangdong Higher Education Institutions of China (No. 05Z018).

\section{References}

[1] A.K. Padhi, K.S. Nanjundaswamy and J.B. Goodenough: J. Electrochem. Soc. Vol. 144 (1997), p. 1188-1194

[2] S.C. Choi: J. Power Sources Vol. 158 (2006), p. 1419-1424

[3] G.X. Wang and J.H. Bradhurst: J. Power Sources Vol. 85 (2000), p. 279-283

[4] C. Ouyang, S. Shi, Z. Wang, X. Huang and L. Chen: Solid State Commun. Vol. 130 (2004), p. 501-506

[5] C.Y. Ouyang, S.Q. Shi and M.S. Lei: J. Alloys Compd. Vol. 474 (2009), p. 370-374

[6] Y. Naoaki and O. Tsutomu: J. Power Sources Vol. 119-121 (2003), p. 171-174

[7] S.K. Jeong and M. Inaba: Electrochim. Acta Vol. 47 (2002), p. 1975-1982

[8] Y. Koyama, I. Tanaka, H. Adachi, Y. Makimura and T. Ohzuku: J. Power Sources Vol. 119-121 
(2003), p. 644-648

[9] H. Tian, N.Q. YE, D. Liu and W.Q. Li: Rare Metals Vol. 27 (2008), p. 575-579

[10]M.D. Levi and G. Salitra: J Electrochem Soc Vol. 146 (1999), p. 1279-1289

[11] M.-H. Lee, Y.-J. Kang, S.-T. Myung and Y.-K. Sun: Electrochim. Acta Vol. 50 (2004), p. 939-948

[12]D.C. Li, M. T and L.Q. Zhang: J. Power Sources Vol. 132 (2004), p. 150-155

[13]H. Kobayashi, Y. Arachi and S. Emura: J. Power Sources Vol. 146 (2005), p. 640-644

[14]J.G. Thevemin and R.H. Muller: J Electrochem Soc Vol. 134 (1987), p. 273-280

[15]J.B. Goodenough: J. Power Sources Vol. 174 (2007), p. 996-1000

[16]A. Würaig, H. Buqa, M. Holzapfel and F. Krumeich: Electrochem. Solid State Lett. Vol. 8 (2005), p. A34-A37 